\title{
Experiences of vulnerability and sources of resilience among immigrants and refugees
}

\author{
Hyacinth Udah \\ Griffith University \\ h.udah@griffith.edu.au \\ Parlo Singh \\ Griffith University \\ parlo.singh@griffith.edu.au \\ Dorothee Hölscher \\ Griffith University \\ d.holscher@griffith.edu.au \\ Jennifer Cartmel \\ Griffith University \\ j.cartmel@griffith.edu.au
}

\begin{abstract}
This article considers the nature of, and factors contributing to, experiences of vulnerability. It also explores some aspects of resilience among immigrants and refugees of black African background in South East Queensland, Australia. The findings indicate that an understanding of what influences immigrants and refugees to engage in activities to mitigate vulnerability can inform the development and implementation of targeted policies, including programs and interventions for successful settlement and integration.
\end{abstract}

\section{Introduction}

Immigrants and refugees ${ }^{1}$ are often described as a vulnerable group (Aysa-Lastra and Cachón, 2012; Bustamante, 2007; Dion, 2010) but they are

\footnotetext{
${ }^{1}$ Immigrants are people who have long-term residence or live permanently in a country other than their countries of birth, while refugees are people who seek protection in safe countries from persecution, torture or killing in their countries of nationality.
} 
also resilient with agency, strengths and capabilities (Aroian and Norris, 2000; Cardoso and Thompson, 2010; Hutchinson and Dorsett, 2012). In the context of liberal societies, the notion of vulnerability as a shared human condition is not self-evident in terms of liberal ideals of independence and autonomy that often escape critique. As a result, there is a tendency to essentialise and label some individuals and groups as either vulnerable that is, dependent, and therefore always a potential drain on society - or as resilient - that is, independent and thus presumably productive members of society, rather than seeing all people as both vulnerable and resilient, albeit in a multitude of variations and degrees. In short, questions of vulnerability and resilience are "sites of political contestation" (Robinson 2010, p.132).

As Robinson (2010) explains, all people must be regarded as vulnerable, inasmuch as degree and nature of this condition of vulnerability will change along a person's lifespan, and in accordance with people's social, political, economic and cultural positioning at different points in their lives. This view rests upon an understanding of social life as a web of relationships and interdependencies. As such, in this article, we accept "the existence of vulnerability without reifying particular individuals [or] groups $\ldots$ as "victims' or 'guardians"' (Robinson, 2010, p.12). Even though immigrants and refugees may appear to be more vulnerable than native-born people, some immigrants and refugees have strengths and capacities and can do remarkably well over the course of their settlement, and even their lifespan. As resilient individuals, these immigrants and refugees do exhibit coping skills effectively to manage adversity and stressful situations at hand, thereby transforming them into less stressful ones and exhibiting positive outcomes (Aroian and Norris, 2000).

Against this background of a relational and contextual understanding of vulnerability and resilience, this article considers not only the nature of, and factors contributing to experiences of vulnerability but also explores some aspects of resilience among immigrants and refugees of black African background in South East Queensland, Australia. The article is organised as follows: First, it presents a brief historical context of African immigration and settlement in Australia. Second, it examines the concepts of vulnerability and resilience. Third, it discusses the study methodology and presents the findings. Finally, it concludes with a discussion on the study findings. The findings indicate that an understanding of what influences immigrants and refugees to engage in activities to mitigate vulnerability can inform the development and implementation of targeted policies, including programs and interventions for successful settlement and integration. 


\section{African immigration and settlement in Australia}

Australia has moved from being the "most British" country in the world to a more diverse, multiethnic and multicultural, society (Jupp, 2002). The 2016 Census results indicate that nearly half (49 per cent) of Australia's population were born overseas (first generation Australian) or had one or both parents born overseas (second generation Australian). At that time, Australians came from nearly 200 countries, spoke more than 300 languages other than English at home, practiced over 100 religions and represented more than 300 ethnic ancestries (Australian Bureau of Statistics (ABS), 2016). Prior to mid-1960, black African immigration was restricted. However, some people of black African descent were in Australia before the Immigration Restriction Act 1901 - the White Australia Policy ${ }^{2}$ — via the First Fleet (for more details, see Pybus, 2006; Udah and Singh, 2018). It was only in the mid-1960s and early 1970s, under the Special Commonwealth African Assistance Plan, that a small number of black African students, from Commonwealth African countries, began to arrive in Australia. Immigration from Africa to Australia reached a peak between 1996 and 2005 with the admission of black African refugees and displaced persons on humanitarian grounds.

In Queensland, the black African population has continued to increase in size. There were only 3,522 African people living in Queensland at the 1986 census but by 2016 the number of sub-Saharan Africans increased to 67,274 ${ }^{3}$ and the number of North Africans to 7,117 (ABS, 2017). Although still a small group, black Africans constitute a highly diverse and rapidly growing population, settling in Queensland as temporary or permanent immigrants. Indeed, the black Africans' lived experience in Queensland presents a unique opportunity to understand immigrant and refugee vulnerability and resilience. While they are most likely to be vulnerable because of the adaptive challenges related to migration and (re)settlement, including their visible difference and foreigner condition, they are a group with resilience.

2 The White Australia policy favoured white immigration, and restricted coloured immigration to Australia. Its implementation was explicitly exclusionary, discriminatory and racist - immigrants were either selected or excluded, and discriminated against based on their ethnicity, skin colour, culture, religion or language (Jones, 2017). The removal of race as a factor for immigration to Australia in 1973, by the Whitlam Labor government, led to the eradication of the White Australia policy.

${ }^{3}$ The problem with these statistics however is that white Africans, especially white South Africans and Zimbabweans, are included in this number. In the 2016 census, there were over 23,436 White South Africans and 5, 295 White Zimbabweans in Queensland (ABS, 2017). 


\section{Towards a relational, contextual understanding of vulnerability and resilience}

"Vulnerability" is a concept that some have applied to understand the experience of various individuals or groups. While the concept of vulnerability is relative and dynamic, it has a commonplace meaning, often associated with poverty, powerlessness, weakness, dependency, limited capacity or susceptibility to injury. As a social concept, the emphasis is placed on how social and economic status inequalities within a society's social order (such as the existence of ethnic and racial discrimination, high rates of unemployment and underemployment, and the lack of resources) render some people and communities more vulnerable than others. Vulnerability denotes, thus, the relative position of advantage or disadvantage that particular individuals or groups occupy within a society (Bankoff, 2004, p. 29). Economically disadvantaged people; racial and ethnic immigrant and refugee minorities; women; children; the aged; lesbian, gay, bisexual, transgender, intersex and queer (LGBTIQ); the homeless; the sick; and persons with disability and other chronic health conditions have all, at times, been labelled vulnerable. Labelling entire groups as vulnerable, while important in pointing to prevailing social injustices, risks essentialising them further, as potentially problematic and dependent populations. Instead, following Robinson's (2010) contention that vulnerability is a shared human condition, there is need to consider what kinds of social, economic and cultural conditions contribute to heightening or lessening experiences of vulnerability among members of particular social groups.

Social groups are rendered vulnerable by barriers preventing access to adequate resources and just recognition, and a lack of visibility and voice in public debates and political decision-making (see Fraser, 2009). This, in turn, can lead to poorer health, physical, psychological, social and economic outcomes (Derose, Escarce and Lurie, 2007). Research shows that immigrants and refugees are hardworking and driven with a strong desire to be in gainful employment rather than on welfare (Fozdar and Hartley, 2013). However, they are more likely to be discriminated against in the labour market (Aysa-Lastra and Cachón, 2012; Colic-Peisker, 2009). Immigrants and refugees are not only discriminated against, and seen as different because of their often-distinctive culture, but also tend to be lumped together and allocated a particular place within the class structure of their receiving society (Rizvi, 1986, p. 19). Frequently, they are concentrated in the lower occupational segments of the working class and experience downward social mobility in their receiving society (Aysa-Lastra and Cachón, 2012). In the case of Australia, visibility (Colic-Peisker, 2009) in terms of difference has 
consequences for racial and ethnic immigrant and refugee minority groups. For example, it can mark them out for differential and sometimes discriminatory treatment in the society and the labour market (Colic-Peisker, 2009; Udah, 2018; Udah and Singh, 2018), potentially placing them in positions of disadvantage and at risk of the negative outcomes summarised above.

Robinson (2010) argues that "levels of vulnerability, and the implication of vulnerability are, in part, a reflection of existing power relations in the context of relationships" (p. 142). The works of Dion (2010), Bustamante (2002; 2007), and Aysa-Lastra and Cachón (2012) illustrate some of the ways in which this contention applied in the case of immigrants and refugees. For example, Dion (2010) argues that among the many challenges confronting immigrants, especially newly arrived immigrants including refugees in their countries of settlement, is "the possibility of experiencing discrimination because of where they came from and who they are, as seen by others through the lens of group labels - ethnicity, race, religion, language" (p. 648). Similarly, Bustamante $(2002 ; 2007)$ uses the notion of vulnerability to describe the social process of labelling immigrants and refugees. He argues that the labelling of immigrants as foreigners significantly contributes to their spatial vulnerability. He defines immigrant vulnerability as "a condition of powerlessness" in which immigrants are socially placed in the society, the economy, and the culture of the country of their settlement (Bustamante, 2007, p. 166).

According to Bustamante (2002, p. 339), there are "structural" and "cultural" dimensions of immigrant vulnerability. The structural dimension derives from the existence of a power structure, which in any given society allocates more power to some than others. The cultural dimension derives from the set of cultural elements (stereotypes, prejudices, racism, xenophobia, ignorance and institutional discrimination) with derogatory meanings, which are used to justify the power differentials between nationals and immigrants. For Bustamante $(2002 ; 2007)$, therefore, immigrant vulnerability begins when a country of destination, exercising its sovereignty, establishes a definition of who is "one of us" and who is "the other", who is "a citizen" and who is "a foreigner" (see also Fraser, 2009). This point was taken further by Aysa-Lastra and Cachón (2012), who suggest that a social outcome of this distinction is the emergence of a discriminatory institutional framework that creates barriers and results in the creation of categorically unequal social subjects or citizens. For Aysa-Lastra and Cachón (2012), immigrant vulnerability derives from their condition as immigrants (and refugees) and their class condition as workers. As Aysa-Lastra and 
Cachón (2012) explain, immigrant vulnerability begins with the state establishing borders and managing (recognising, guaranteeing, or denying) individual rights as well as distinguishing between the insiders and the outsiders. Thus, if immigrants and refugees appear to be more vulnerable than native-born people, it is because of the ways in which they have been constructed through norms of ethnicity, race, skin colour, religion, and language, including effective lack of resources, institutional barriers, class position and participation in their new countries.

While important, Dion's (2010), Bustamante's (2002; 2007) and AysaLastra and Cachón's (2012) arguments risk defining immigrants and refugees as vulnerable without recognising their resilience in the face of extraordinary life circumstances. Without denying the significance of discriminatory barriers and challenges faced by immigrants and refugees in their recipient countries, the immigrant experience must also be seen as one of resilience. For example, when immigrants and refugees are looked at through a lens of individual strengths, passions and skills, they appear also to be highly resilient people who go on to thrive in their receiving society (see Aroian and Norris, 2000; Cardoso and Thompson, 2010; Hutchinson and Dorsett, 2012).

The term resilience has multiple uses, depending on the field. In relation to individuals and groups (for example, families, immigrant and refugee groups), resilience may be a description of a personality characteristic or coping resource or skill they have when, in the face of barriers and challenges associated with inequality, discrimination and disadvantaged circumstances, they overcome adversity, survive stress, rise above marginalisation, or disadvantage and thrive successfully (Aroian and Norris, 2000; Cardoso and Thompson, 2010; Ungar, 2008). In this sense, resilience "connotes inner strength, competence, optimism, flexibility and the ability to cope effectively when faced with adversity" (Wagnild and Collins, 2009, p. 29). Thus, resilience is less an individual trait than a quality of an individual's personal, social, economic, political and cultural ecology and as such, denotes "a dynamic process that requires both the exposure to risk and the manifestation of positive adjustment despite experiences of adversity and trauma" (Cardoso and Thompson 2010, p. 257). Moreover, Ungar (2011, p. 10) explains that in the context of exposure to significant adversity, resilience is,

both the capacity of individuals to navigate their way to the psychological, social, cultural, and physical resources that sustain their wellbeing and their capacity individually and collectively to negotiate for these resources to be provided and experienced in [contextually and] culturally meaningful ways. 
Ungar understands navigation to refer to personal agency and motivation to search for what one needs in order to do well, as well as pushing oneself to access any such opportunities and resources that are made available by power holders to those who are disadvantaged. On the other hand, negotiation refers to how persons, individually or in groups, ascribe meaning to any available and accessible resources. Importantly, Ungar (2008, 2011) maintains that, sometimes, people do not accept or utilise available opportunities because of the principle of negotiation: what people are given must match with what they need or with their culturally embedded meaning systems and social reference groups.

In sum then, working within a relational and contextual understanding of vulnerability and resilience, immigrants and refugees are rendered vulnerable by adverse conditions such as discrimination, marginalisation and inequality, and may be at risk of multiple negative outcomes. Yet, care must be taken not to define them in terms of these contextual conditions and the risks that they entail. Equally important are sources of resilience, which they may derive from their "assets" — that is, positive individual adaptive capacities linked to competencies and skills; hopes, interests and motivation; as well as self-esteem, intellect, and the ability to self-regulate — and from their "resources" - that is, positive external influences provided, for example through family and community support; schools, neighbourhood relations, cultural and religious affiliations (Cardoso and Thompson, 2010). Possession of both "assets" and "resources" are necessary for immigrants and refugees to overcome, to recover after experiences of difficulties, and ultimately, to settle in the face of adversities and contextual barriers in the economic, social, cultural and political dimensions of the societies that they have joined. Potential resilience is thus conceptualised, in this article, as the steps, or proactive actions, taken by immigrants and refugees that make them resilient and more likely to succeed and thrive after experiences of difficulties (Hahn, Willis, Christie, and Matthews, 2017). From this perspective, potential resilience is more than mere capacity to survive. It involves identifying potential barriers and risks, forming supportive relationships and taking proactive steps or adjustments in order to navigate and negotiate available or potentially available resources. In the next section, we present our methodology.

\section{Method}

This article draws on data from a broader research study that explored the lived experiences of adult immigrants and refugees from African nations residing in South East Queensland. The study focused on how these 
immigrants and refugees define their identity, personal and socioeconomic wellbeing and sense of belonging in white majority Australia. Qualitative research methods were utilised to collect and systematically analyse data.

In-depth semi-structured individual interviews were conducted from April to July 2014 by the first author. Interviews were carried out in the English language. The interviews were exploratory and stimulated the narration of experiences that would remain unexpressed within a questionnaire format. The interview questions focused on participants' migration and settlement experiences, personal and socioeconomic conditions, employment, satisfaction, wellbeing and sense of belonging. Most interviews took place in participants' homes and were audio-recorded and transcribed verbatim. All participants gave written consent. Participants $(\mathrm{N}=30)$ consisted of black African (10 females and 20 males) adults, between the ages of 22 and 67 years. Of these participants, 17 (56.7 percent) came as refugees through Australia's humanitarian program and 13 (43.3 percent) came as temporary migrants (six arrived on student visa and seven on skilled migration visa). These participants were selected through our personal, professional and community contacts. Purposeful sampling was used to select participants who had lived in Australia for more than 3 years. Further, they were selected because of their level of education - a third of the participants hold a bachelor's degree and two have a doctorate degree- as well as their English proficiency, both factors important in promoting civic participation. While the participants vary in their demographic characteristics, most have tertiary qualifications and professional expertise, which are much sought after in today's knowledge-based economy (Udah, Singh and Chamberlain, 2019). In addition, many of the participants are naturalised Australian citizens. A few are permanent legal residents of Australia. The remarkable feature of the participants was the diversity of their culture, religion, values, languages, heritage and national backgrounds. ${ }^{4}$ The participants have been given pseudonyms to protect their identity.

Thematic analysis was used to identify common thematic elements across the participants' transcribed interview data (Braun and Clarke, 2006). During the coding, we searched for keywords, buzzwords and metaphors to support analysis and interpretation. The coding process helped to identify and produce a concise matrix of key emerging themes. Some of the important themes that emerged involved the vulnerability and potential resilience of

${ }^{4}$ Participants came from Ghana, Liberia, Nigeria, and Sierra Leone in West Africa; Tanzania and Uganda in East Africa; Congo and Rwanda in Central Africa; Eritrea, Somalia, Sudan and South Sudan in Northeast Africa; and Botswana and Zimbabwe in Southern Africa. 
participants. As visible immigrants, many participants perceived themselves to be vulnerable and at disadvantage. This was experienced in differential treatment and challenges faced, particularly, in securing jobs. Regardless of their considerable barriers and challenges, participants also demonstrated potential resilience.

\section{Results}

On the grounds of being visibly different in white dominated Australia, many participants identified themselves as vulnerable and disadvantaged. While the markers of their visible and cultural difference - skin colour, physical and facial features, accent, dress or religion — together with other random characteristics and discriminatory factors contribute to a considerable level of their vulnerability and disadvantage, some participants demonstrated potential resilience and coped effectively in the face of adversity. They maintained hope, showed perseverance, took initiatives to make things happen by going back to school and upskilling themselves, and received support from families and communities.

A telling example in this respect is the experience of Aaron, aged sixtyfive, an academic with a $\mathrm{PhD}$. Aaron is one of the older participants in this study. Aaron is very passionate about education, equity and diversity. He was a university lecturer in the Democratic Republic of Congo (former Zaire) before coming to Australia in 1987 as a political refugee. While he had no trouble speaking English, one of Aaron's greatest challenges on arrival to Australia was finding employment. His overseas educational qualifications were not recognised on time. According to Aaron:

The only precious asset I carried with me on arrival consisted of my educational qualifications, my Bachelor of Arts with Honours and doctorate degree. I submitted them to the Council of Overseas Professional Qualifications (COPQ) for recognition. It was finalised only two years later. Their initial assessment was that my overall qualification was comparable to a three-year bachelor's degree in Australian standard. Their assessment was shocking to me. I fought and told them that their assessment was misleading. After I confronted them with the United Nations Educational, Scientific and Cultural Organisation (UNESCO) assessment of my BA alone undertaken earlier where my BA was aligned with a Belgian or a French $B A$, they consulted with an independent assessor of 
their choice who stated finally that my overall qualification was comparable to an Australian PhD.

While the UNESCO assessment equated Aaron's Bachelor of Arts with Honours with a Belgian or a French Bachelor of Arts with Honours degree, the Australian assessment downgraded all his qualifications to a three-year bachelor's degree in Australian standard. Though the experience was traumatic, frustrating and depressing, Aaron showed perseverance and demonstrated resilience. Not only was he persistent, he took initiative to make things happen for himself.

Aaron was ready to apply for any job, but it was not easy because of the long delay in recognising his overseas qualifications. While waiting for the qualifications to be recognised, he went back to university and undertook a new degree to find employment. As Aaron said,

\section{After all the hassle, I realised that it will be too hard for me to get a job with my African credentials. I did not wait for my PhD recognition before I decided to enrol at uni[versity] in order to prepare for another degree. Believe me; you have to be very strong not to fall into depression in such situations}

Frese and Fay (2001) define initiative as "behaviour characterised by its self-starting nature, its proactive approach, and by being persistent in overcoming difficulties that arise in pursuit of a goal" (p. 134). Rather than remaining a victim, Aaron took proactive action to overcome barriers and setbacks. One consequence of Aaron's action is that things changed for him (Frese and Fay, 2001). His perseverance and proactive action helped him to take control and improve his situation. As Aroian and Norris (2000, p. 55) explain, resilient individuals view change as "inevitable, challenging, and manageable". Similarly, Aaron saw change as inevitable. He had a positive outlook on life. Aaron was able to appraise the situation and came to terms with aspects of his life that are uncontrollable (Aroian and Norris, 2000). The delay in recognising his qualifications could have undermined his mental health and overall wellbeing, but his resiliency helped him to seek solutions in an efficient manner.

Aaron is well educated, scholarly and well versed in art, languages and literature but his condition on arrival was such that he could fall into depression. He faced many barriers, hurdles and setbacks. First, Aaron is a black refugee and comes from a French speaking country. Though his English proficiency is high, he has accent and lacks the local qualifications, 
work experience, referees and social networks, which are significant barriers to satisfactory employment in Australia. As a former university lecturer, Aaron thought he would have had a range of options in academia. However, as Aaron said:

Those position vacancies were not available for someone without local experience. Advertising them was just a formality as someone may be working in the position ad interim. Therefore, there is a high chance the position will be given to the incumbent officer; to someone they know. It was useless applying for.

It could be suggested from the data extract that Aaron's condition had the effect of discouraging him from applying for certain jobs. Though he felt it was useless applying for academic jobs, he never gave up. He maintained a sense of optimism, negotiated (Ungar, 2011) and sought help. For example, he described receiving support from a university professor who gave him the first opportunity to work as a research assistant.

Aaron described himself as one of the multi-disadvantaged people in Australia:

When you look at my background, I am part of a multidisadvantaged people in Australia. ... For people like me, we do not have local experience and as such we lack the networks and local referees. This explains why I looked for jobs for long. It was not because of my inability to do research but because I was victimised in the name of those sets of disadvantages and vicious circles that are so hard to break.

This explanation captures some of the barriers associated with migration and resettlement facing some immigrants and refugees in Australia. The barriers are not just peculiar to Aaron. One participant, Brian from Nigeria, said that at the time of his arrival in the 1990s,

Most Africans that came during that time had similar issues. Their experiences back home were not recognised here. You have to go back and do some other jobs. Even when you are looking for jobs that you think you are way above; the same issue comes again. 
As past studies have shown, the non-recognition of qualifications obtained overseas is one of the systemic barriers that immigrants and refugees encounter (Colic-Peisker and Fozdar, 2006; Fodzar and Hartley, 2013). For example, Bruno, from Rwanda, explained, "Most Africans do not get the job they want ... because their previous qualifications are not recognisable here. I give an example of myself. I had to retrain myself".

Like Aaron, Bruno was resilient. To overcome what Colic-Peisker and Fodzar (2006, p. 221) have described as "mechanisms of institutional discrimination" - the failure to recognise overseas' qualifications and the barriers erected by trade and professional associations - Bruno went back to school and retrained himself. He studied social work, which helped him to enter and stay in employment.

As some scholars have argued, employment is one of the primary indicators of immigrant and refugee successful settlement and integration (Hebbani and Colic-Peisker, 2012). Employment is not only important for immigrants and refugees' material and social wellbeing, but also is critical to their self-empowerment and interaction with the broader community. Gaining employment can alleviate many of the acculturative stresses associated with settlement (Hebbani and Colic-Peisker, 2012) and influence an immigrant or refugee's social standing and overall wellbeing (Fozdar and Hartley, 2013). However, the analysis of many participants' accounts suggests that they faced barriers in the pursuit of employment. While the job hunt journey is a huge task, this task can be harder for many ethnic minority immigrants and refugees: Either their qualifications are not recognised or, when they are, other obstacles such as lack of local work experience make it difficult for them to secure employment (Colic-Peisker and Tilbury, 2007). For example, some participants saw the demand for Australian work experience by employers as one of the reasons they had trouble securing employment. As one participant, Tanya, from Somalia, stated, "Most Australian employers will always ask for Australian work experience." Describing her experiences, Margaret, explained:

Trying to get a job and they are talking about we want someone with local experience. That to me was a bit frustrating. Some jobs I thought I was qualified, sometimes I found it was different; I do not have the local experience. I found myself competing with people with local experience. So, it is a difficult challenge. 
The quote above shows Margaret's desire to find jobs commensurate to her qualifications. Margaret migrated to Australia in 2005 as a skilled migrant. She was educated in Zimbabwe where she had many years of working experience in the banking sector. However, she was impeded from entering the Australian labour market by her lack of local work experience. Despite the difficulties, Margaret was resilient and developed plans to deal with impending or future difficulties. First, she did not stop looking for other jobs, which suit her and are right for her. Instead of resigning herself to institutional barriers or giving up in the face of difficulties, she was persistent and tried other things to improve her condition. According to Margaret:

\begin{abstract}
The way I dealt with it is to accept a job lesser than what I thought I would have wanted to be doing and trying to improve myself and going into another area and doing something else. For instance, I have completed a diploma in interior design. It is one of the ways of coping with life and getting more satisfaction out of life.
\end{abstract}

Thus it appears that Margaret demonstrated agency and a capacity for resilience. In the face of her challenges, she upskilled and expanded her capabilities by completing a diploma. As Aysa-Lastra and Cachón (2012) explain, immigrants are likely to adjust more quickly than native-born people to labour market conditions because of their resilience to look for and accept any job they can find. Being resilient, Margaret navigated (Ungar, 2011) and tried other things that she needed and might help her for a job. In addition, Margaret took an active approach and received support in contextually and culturally meaningful ways from her Zimbabwean community, especially through religious activities.

Given the difficulty experienced breaking into the labour market, several participants believed that for them to enter and stay in employment, they must take an active and self-starting approach to overcome the barriers and setbacks that arise in securing employment. Lamenting the difficulties experienced by black Africans, Kevin stressed that few people in Australia,

believe that we, as the African people, have the potential to be higher achievers, the potential to be higher performers in working in an office. It could be because of what is portrayed of us in the media. Nothing good is really said about us in the media. It could be, perhaps, racism. You know, it is very difficult to say. But I know one thing for sure, we are always 
thought of as under-achievers rather than people who have the potential to achieve and be successful .... I think we need people that can project something different to what society thinks of us.

Unlike Aaron and Margaret, Kevin completed his degrees, both bachelor's and master's, in Queensland. Kevin was born in South Sudan. He came to Australia in 2005 to seek refuge. He was a teenager when he arrived with his family. At the time of this interview, Kevin's most significant concern was getting a job after graduation. He said that he applied for several job positions and got no response. He believed that his chance of getting a job commensurate with his qualifications is minimal because of his racialised skin colour, and how people think of, and essentialise, black Africans - that is, as inferior, incapable, dependent and thus presumably less productive members of society.

According to Kevin, "not being seen as part of this society is heartbreaking." He believed that "people are miseducated about African people." For Kevin, this miseducation sustains many of the misperceptions being circulated and held about black Africans in Australia. As Kevin stated:
A lot of us are unemployed and people are blaming us so much on relying on welfare. I think the reason for relying on welfare is not because we are lazy people. It is because no one wants to give us a job. It could be because of our skin colour.

Instead of seeing himself as a victim, an acceptance of the effects of skin colour, a positive outlook on life and encouragement from family members helped Kevin to be resilient. For example, Kevin explained that his mother,

would always say to me, something, sometimes, requires courage. You will continue to try. ... That I don't get a job because of the colour of my skin cannot be compared to trials I have been through before coming here. I have not given up on trying. What keeps me going is in knowing where I come from and the tough experiences that I have had in life and I think this is what pushes me. This is what keeps driving me and because of that I will keep trying to achieve that dream, that better life that I never had before.

Kevin demonstrated optimism and hope. As Snyder, Irving and Anderson (1991) have indicated, people with higher hopes about the present and the 
future set goals for themselves, tend to be courageous, motivated and determined to attain their goals, and actually attain the goals more often, especially when faced with obstacles. Kevin's positive motivational state, based on his sense of determination, capabilities and hard work ethics, was a driving force behind everything he did to cope with difficulties and thrive. As Kevin stated, "for me as an African to realise my dream here, I believe I should work twice as hard."

Like Kevin, other participants believed that to overcome their difficulties and realise their dreams in Australia, they must adopt diligent work ethics. Damian, a computer professional from Ghana, stated, "You really have to do twice as much to be seen as half as good. ... I have to work twice as hard to be able to get anywhere." As an information technology specialist, he believed that resilience and diligent work ethics could make all the difference for Africans in Australia. However, beyond this, many participants' knowledge of their barriers, including their positive outlook on life, support from families and communities, individual sense of determination and capabilities helped them to take proactive steps that made them resilient in the pursuit of their dreams of better life in Australia.

\section{Discussion and Conclusions}

Although this study explored subjective views, experiences and perspectives of a small sample group of participants, the findings make a useful contribution to the growing body of work that seeks to understand the experiences of black Africans in Australia, and the literature on the strengths, capacities and resilience of immigrants and refugees from culturally and linguistically diverse backgrounds (Cardoso and Thompson, 2010; Fodzar and Hartley, 2013; Hutchinson and Dorsett, 2012). While much has been written on the barriers and challenges associated with migration and resettlement confronting African immigrants and refugees (Colic-Peisker, 2009; Colic-Peisker and Tilbury, 2007; Hebbani and Colic-Peisker, 2012), there is evidence, in this article, of the existence of resilience and some factors associated with it.

Despite the barriers and challenges, some participants become more resilient. Resilient individuals tend to understand what is happening to them, and are able to distinguish between what is controllable and what is not, choose effective means of coping, and select and modify more supportive environments (Cardoso and Thompson, 2010; Hutchinson and Dorsett, 2012; Wagnild and Collins, 2009). As resilient people, some participants thrived economically and socially. They were optimistic about the future and took proactive steps, summoned up resources, and coped (Saleebey, 1992). Some 
features contributing to their resilience include positive individual, family, cultural, religious and community factors (Cardoso and Thompson, 2010; Hutchinson and Dorsett, 2012). Therefore, through increased insight into our participants' perceived experiences, this article inspires individual and institutional action to recognise the strengths, capacities and resilience of immigrants and refugees and promote their inclusion and active civic participation.

Based on the participants' accounts, some immigrants and refugees have capacities and strengths, which they can tap into and build on to ensure that they are able to maintain socially competent behaviours, and thrive in their communities (Pasteur, 2011). This calls for changing community and wider society attitudes towards immigrants and refugees. However, whilst efforts are being made to eliminate discrimination and empower immigrants and refugees, often, negative media coverage and political discourses remain a concern. Constant pathologisation of immigrants and refugees not only denies their inherent resilience but also has the potential to alienate them from full inclusion into the community and society (Hutchinson and Dorsett, 2012). It is, therefore, crucial for everyone: the media, government, professionals and general population to refrain from using deficit models to describe and define immigrants and refugees. The tendency to use a purely deficit-based model devalues them and reinforces the view that they are a liability, and therefore, always a potential burden on society. Indeed, a shift away from the deficit model to one that focuses on empowerment and fostering the building of social networks and strengths would improve this (Fozdar and Hartley, 2013). Focusing more attention on their strengths and resources, rather than on their shortcomings and victim story to the neglect of their potential resilience, would go a long way to improve their wellbeing, sense of belonging, and increase a more satisfying life for them (Fozdar and Hartley, 2013; Hutchinson and Dorsett, 2012).

In addition, a better understanding of resilience in immigrants and refugees and what influences them to engage in activities to mitigate vulnerability can inform, and contribute to the development and implementation of policies and programs to foster their resilience and facilitate successful settlement and integration. For example, the mere presence of services to support settlement and integration of immigrants and refugees in Australia and comparable countries does not mean that they will always step up and use these services. If these services are not provided in ways that are culturally meaningful and relevant to them (perhaps due to experiences of racism and discrimination), then, their resilience remains contingent on their negotiation for a place or service that is more inclusive 
and responsive to their context and cultural realities (Ungar, 2008). Thus, essential for fostering resilience in immigrants and refugees is a proactive stance on the part of government and professionals working with them to negotiate and provide them with what they might need in a culturally meaningful and relevant way. This involves understanding what resources they have and analysing how they have survived, what they have done, what they have learned from doing it, and how they can be assisted to access appropriate programs, activities and services relevant to their needs (Cardoso and Thompson, 2010; Hutchinson and Dorsett, 2012; Saleebey, 1992). In this case, it is to give them opportunities both plentiful and meaningfulopportunities to break the cycle of disadvantage, enter the mainstream labour market and surmount their challenging circumstances regardless of their religion, sex, age, gender, sexual orientation, migration pathways or citizenship status, postcodes or where they settle and live.

To determine and understand immigrant and refugee vulnerability, two questions need asking. First, to what challenges are they vulnerable? Second, what makes them vulnerable and disadvantaged? Several factors contribute to our participants' vulnerability. These include, but are not limited to: (a) their immigrant and class condition; (b) failure to recognise their qualifications obtained overseas; (c) assumptions that their educational and work experience cannot be translated to the Australian context; (d) their accent equated with lack of English language proficiency; and (e) their skin colour, especially dark skin, equated with a racialised identity. While factors such as non-recognition of overseas qualifications and lack of Australian work experience continue to marginalise and act as impediments in securing employment for many immigrants and refugees (Colic-Peisker and Tilbury, 2007; Udah, 2018), skin colour and accent add additional layers of marginalisation and exclusion for our participants (Udah, Singh and Chamberlain, 2019). This means that they are more likely to be treated differently and disadvantaged by prejudices, or bias or discrimination. While the discrimination against skin colour and accent is non-direct, the discrimination against educational qualifications and overseas work experience seems direct and committed by institutions that make the assessments. Therefore, the findings in this article are important to exploring the structural, interpersonal and cultural conditions that have produced and continue to produce their disadvantage, and the conditions that need to be put in place to readdress their vulnerability, social and economic inequalities.

In diversified and multicultural countries like Australia, counteracting immigrant and refugee disadvantage may require incorporating inclusive practices that include anti-oppressive and anti-racism education in schools, 
classrooms, and workplaces. It may also require counteracting negative discourses, promoting diversity and social justice, providing job training and placement and addressing employment discrimination and employers' prejudices or preferences or reluctance to employ new immigrant and refugee arrivals with overseas qualifications or non-Australian Standard accent through ongoing conversation on race relations, and on the barriers and challenges that are ever-present and confront immigrants and refugees (Colic-Peisker and Tilbury, 2007; Udah, Singh and Chamberlain, 2019). Hence, this article is an invitation to promote social inclusion and healthy community environments. Further research with a larger sample size is needed to check whether the findings reported in this article are the same or match well with national trends. Future research is also needed, particularly, to examine and explain why some immigrants and refugees are resilient and some are not.

\section{References}

Aroian, K., and Norris, A. (2000). Resilience, stress, and depression among Russian immigrants to Israel. Western Journal of Nursing Research, 22(1), 54-67

Australian Bureau of Statistics (ABS). (2017). 2016 census quickStats. http://www.censusdata.abs.gov.au/census services/getproduct/censu s/2016/quickstat/036?opendocument

Australian Bureau of Statistics. (2016). Cultural diversity. http://www.abs.gov.au/ausstats/abs@.nsf/Latestproducts/2024.0Main \%20Features 22016

Australian Bureau of Statistics. (2012). Regional Population Growth, Australia, 2010-11. https://www.abs.gov.au/ausstats/abs@.nsf/ Products/3218.0 2010-11 Main+Features $\sim$ Queensland

Aysa-Lastra, M., and Cachón, L. (2012). Latino immigrant employment during the great recession: A comparison of the United States and Spain. Norteamérica, 7(2), 7-42.

Bankoff, G. (2004). The historical geography of disaster: "Vulnerability" and "local knowledge" in Western discourse. In G. Bankoff, G. Frerks and D. Hilhorst (Eds.), Mapping vulnerability: Disasters, development and people (pp. 25-36). London: Earthscan.

Braun, V., and Clarke, V. (2006). Using thematic analysis in psychology. Qualitative Research in Psychology, 3(2), 77-101.

Bustamante, J. (2002). Immigrants' vulnerability as subjects of human rights. International Migration Review, 36(2), 333-354. 
Bustamante, J. (2007). A dialectical understanding of the vulnerability of international migrants. In H. Vera and J. Feagin (Eds.), Handbook of the sociology of racial and ethnic relations (pp. 161-192). New York: Springer.

Cardoso, J., and Thompson, S. (2010). Common themes of resilience among Latino immigrant families: A systematic review of the literature. Families in Society: The Journal of Contemporary Social Services, 91(3), 257-265.

Colic-Peisker, V. (2009). Visibility, settlement success and life satisfaction in three refugee communities in Australia. Ethnicities, 9(2), 175 -199.

Colic-Peisker, V., and Fozdar, F. (2006). Employment niches for recent refugees: Segmented labour market of the 21st century Australia. Journal of Refugee Studies, 19(2), 203-229.

Colic-Peisker, V., and Tilbury, F. (2007). Refugees and employment: The effect of visible difference on discrimination. Perth: Centre for Social and Community Research, Murdoch University.

Derose, K., Escarce, J., and Lurie, N. (2007). Immigrants and health care: Sources of vulnerability. Health Affairs, 26(5), 1258-1268.

Dion, K. (2010). Understanding immigrants' experiences: Reflections on Ken Dion's research contributions. Journal of Social Issues, 66(4), 648-652.

Fodzar, F., and Hartley, L. (2013). Refugee resettlement in Australia: What we know and need to know. Refugee Survey Quarterly, 32(3), 23-51.

Fraser, N. (2009). Scales of justice: Reimagining political space in a globalising world. Cambridge: Polity Press.

Frese, M., and Fay, D. (2001). Personal initiative: An active performance concept for work in the 21st century. Research in Organizational Behavior, 23, 133-187.

Hahn, D., Willis, T., Christie, A., and Matthews, S. (2017). The relationship between social capital and potential resilience in individuals. Journal of Emergency Management, 15(3), 189-194.

Hebbani, A., and Colic-Peisker, V. (2012). Communicating one's way to employment: A case study of African settlers in Brisbane, Australia. Journal of Intercultural Studies, 33(5), 529-547.

Hutchinson, M., and Dorsett, P. (2012). What does the literature say about resilience in refugee people? Implications for practice. Journal of Social Inclusion, 3(2), 55-78

Jelle, H., Guerin, P., and Dyer, S. (2006). Somali women's experiences in paid employment in New Zealand. New Zealand Journal of Employment Relations, 3(2), 61-70. 
Jones, B. (2017). Australian politics explainer: The white Australia policy. Retrieved from http://theconversation.com/australian-politicsexplainer-the-white-australia-policy-74084

Jupp, J. (2002). From white Australia to Woomera: The story of Australian immigration. New York: Cambridge University Press.

Pasteur, K. (2011). From vulnerability to resilience: A framework for analysis and action to build community resilience. Rugby, Warwickshire, UK: Practical Action Publishing

Pybus, C. (2006). Race relations and early Australian settlement. Sydney Papers, 18(3-4), 38-48.

Rizvi, F. (1986). Ethnicity, class and multicultural education. Waurn Ponds, Victoria: Deakin University.

Robinson, F. (2010). After liberalism in world politics? Towards an international political theory of care. Ethics and Social welfare, 4(2), 130-144.

Saleebey, D. (1992). The strengths perspective in social work practice. New York: Longman.

Snyder, C., Irving, L., and Anderson, J. (1991). Hope and health: Measuring the will and the ways. In C. R. Snyder and D. R. Forsyth (Eds.), Handbook of social and clinical psychology: The health perspective (pp. 285-305). Elmsford, NY: Pergamon Press.

Udah, H. (2018). "Not by default accepted": The African experience of Othering and being Othered in Australia. Journal of Asian and African Studies, 53(3), 384-400.

Udah, H., and Singh, P. (2018). "It still matters": The role of skin colour in everyday life and realities of black African migrants and refugees in Australia. Australasian Review of African Studies, 39(2), 19-47.

Udah, H., Singh, P., and Chamberlain, S. (2019). Settlement and employment outcomes of black African immigrants in Southeast Queensland, Australia. Asian and Pacific Migration Journal, 28(1), 1-22.

Ungar, M. (2011). The social ecology of resilience: Addressing contextual and cultural ambiguity of a nascent construct. American Journal of Orthopsychiatry, 81(1), 1-17.

Ungar, M. (2008). Resilience across cultures. British Journal of Social Work, 38(2), 218-235.

Wagnild, G., and Collins, J. (2009). Assessing resilience. Journal of Psychosocial Nursing, 47(12), 28-33. 